\title{
Notes on the vocalizations of Yellowish Pipit (Anthus lutescens)
}

Peter Boesman

In the following we briefly analyze and compare voice of the different races of Yellowish Pipit (Anthus lutescens). We also try to quantify the extent of any vocal differences using the criteria proposed by Tobias et al. (2010), as a support for taxonomic review.

We have made use of sound recordings available on-line from Xeno Canto (XC).

Difference in voice between nominate and peruvianus has already been pointed out (Schulenberg et al. 2007). A comparison of song per race with sonograms:

$\underline{\text { nominate }}$

Colombia

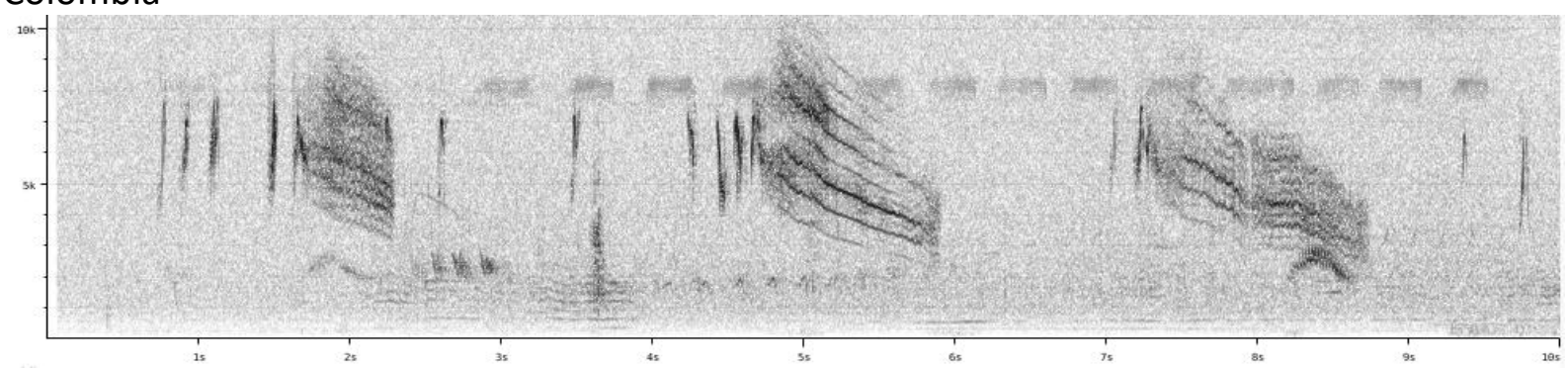

French Guyana
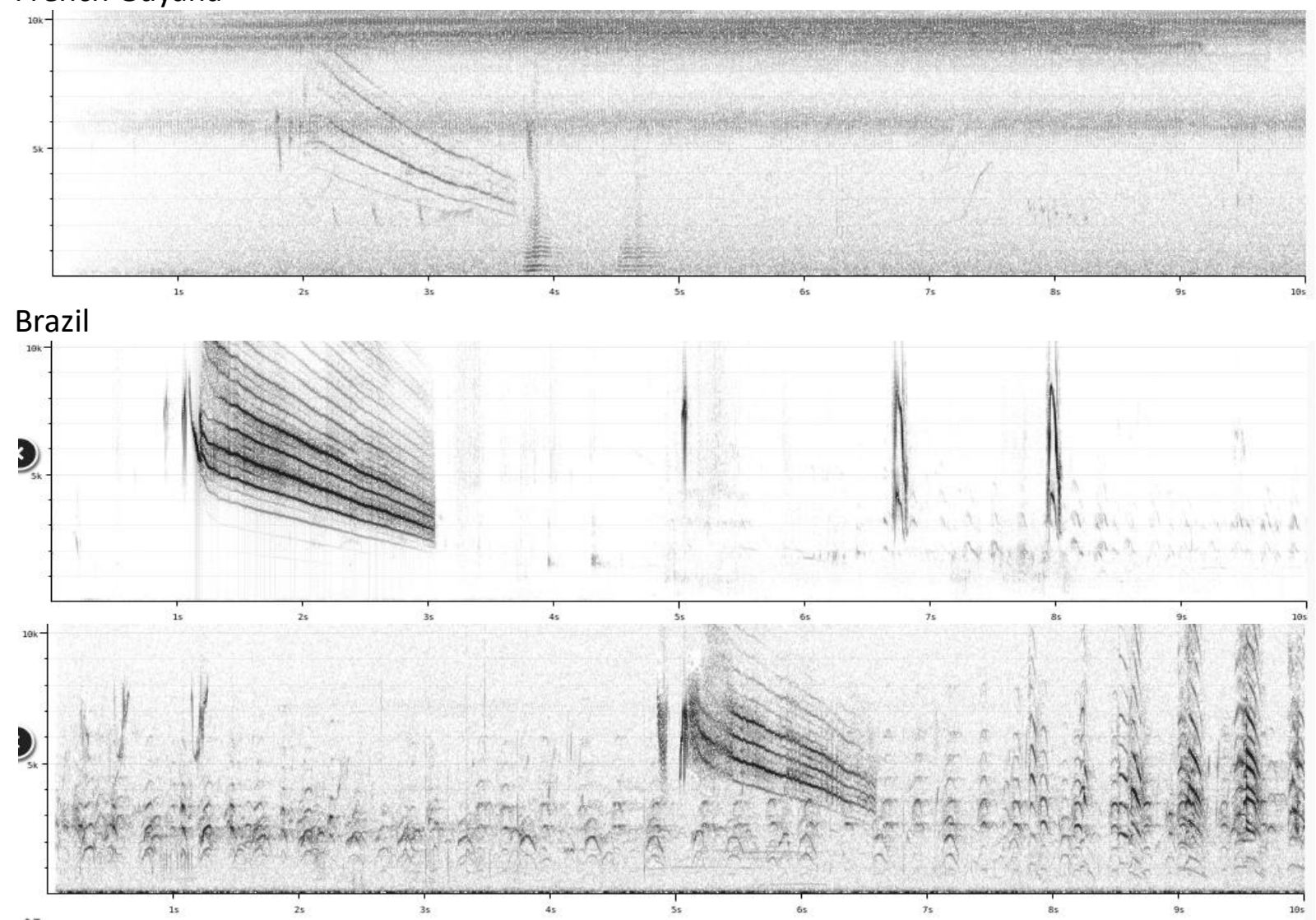


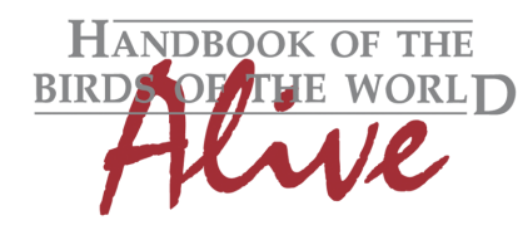

\section{ORNITHOLOGICAL NOTES}

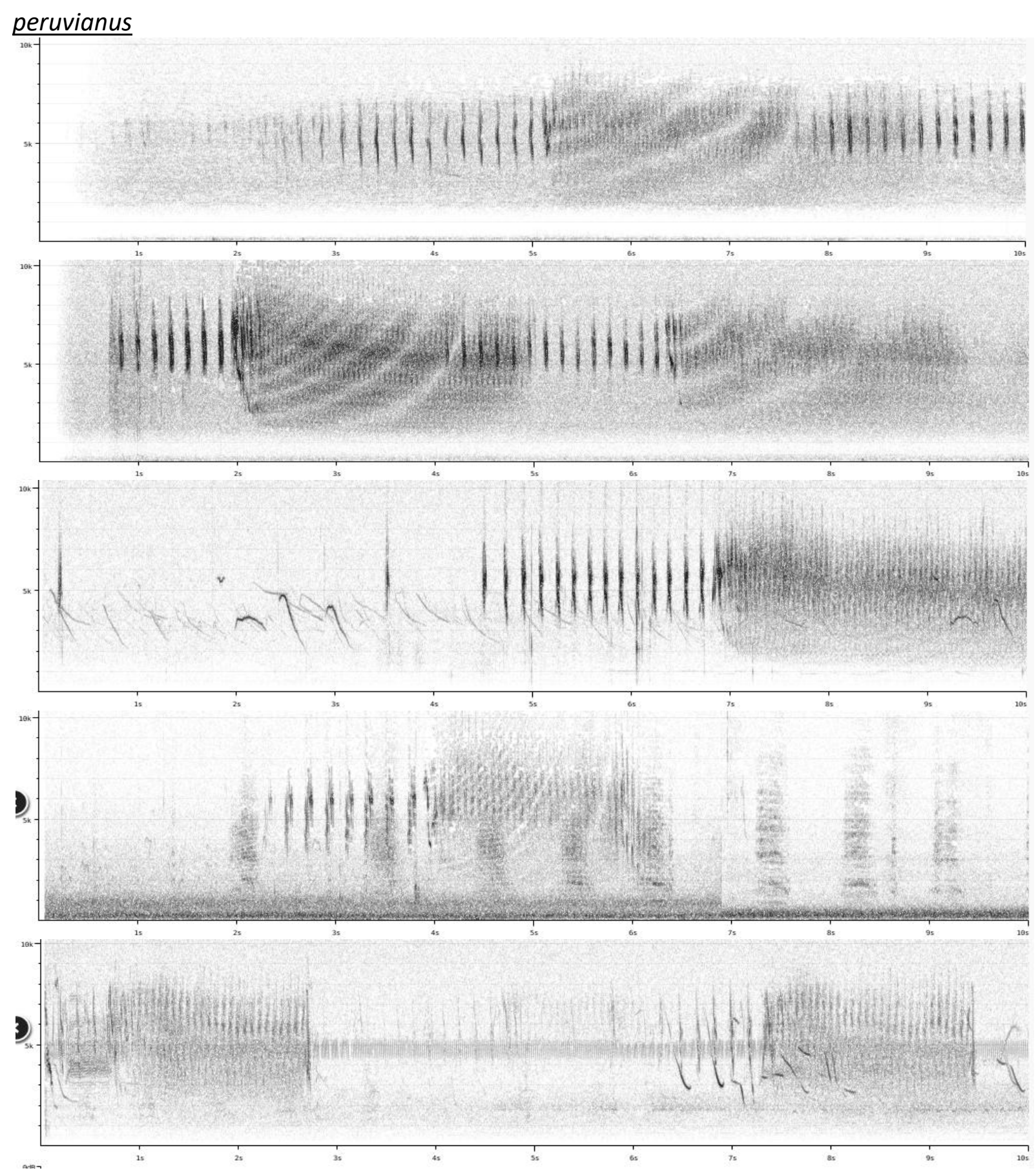

From the above examples, differences in song are quite clear:

Song of nominate typically starts with 1-3 short notes (occasionally a few more, when flying up for display-flight) followed by a very nasal buzz descending in pitch, with a duration of 1$2 \mathrm{~s}$. This is valid over the entire (large!) range of this taxon.

Song of peruvianus starts with a rather long series (6-16) of short notes given at regular pace, followed by a strange drawn-out buzzy or sizzling 'note', which often ends with a finishing short high-pitched note (duration 2-4s). 

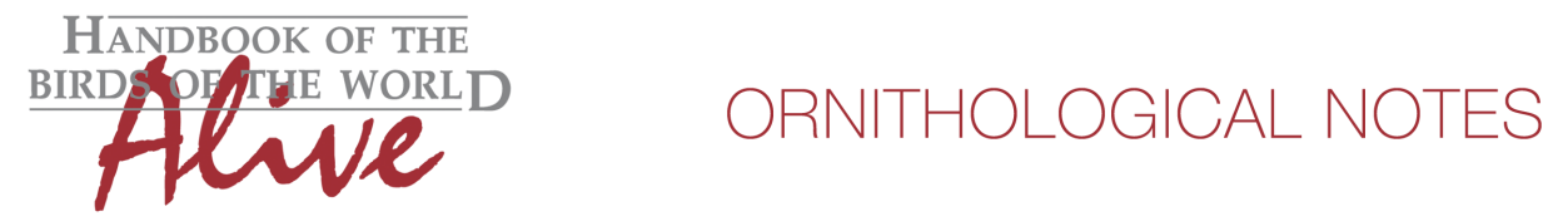

The sizzling note of peruvianus is quite peculiar. How exactly the sound is produced is not clear, but when zooming in on the time scale of a sonogram, one can actually see that it is a very fast series of separate short notes, unlike the continuous long note of nominate:

peruvianus

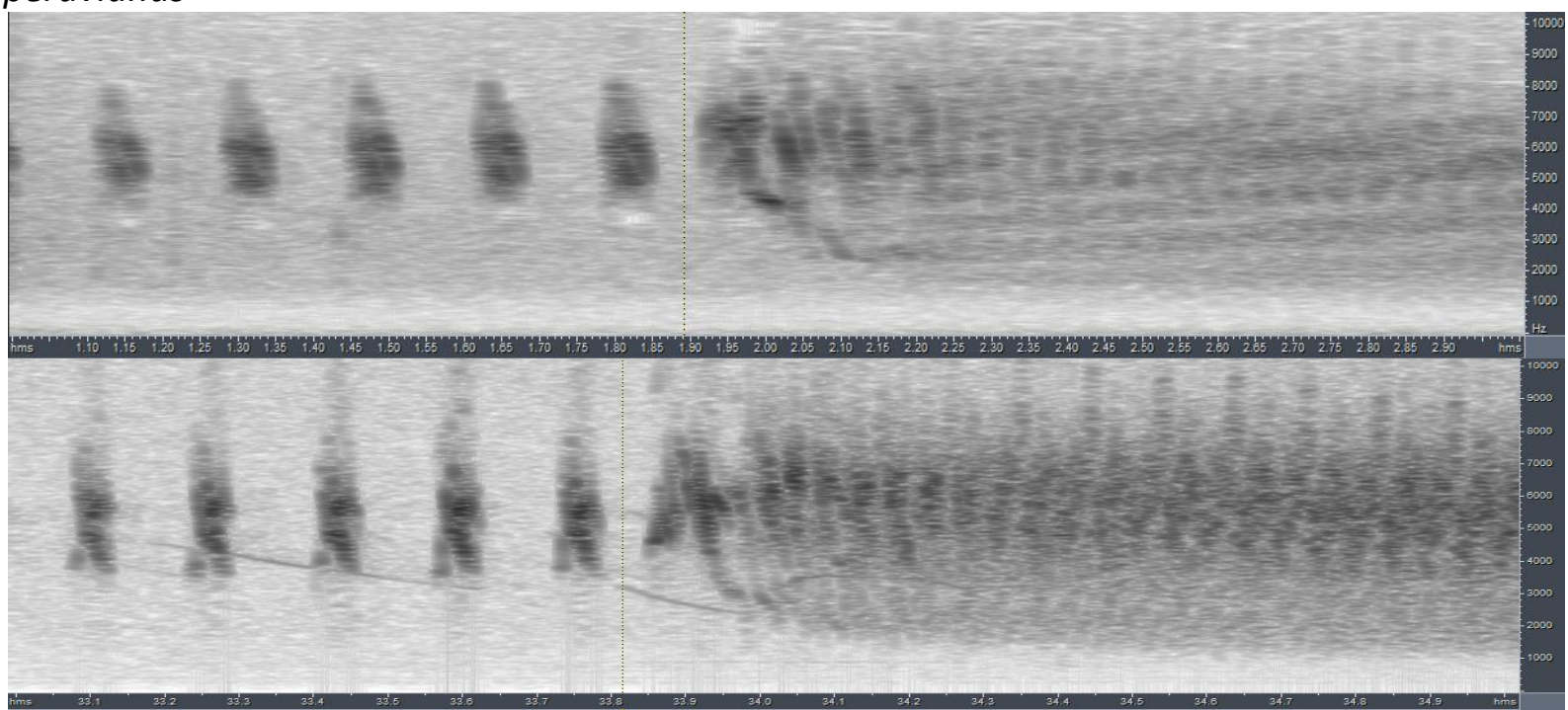

nominate

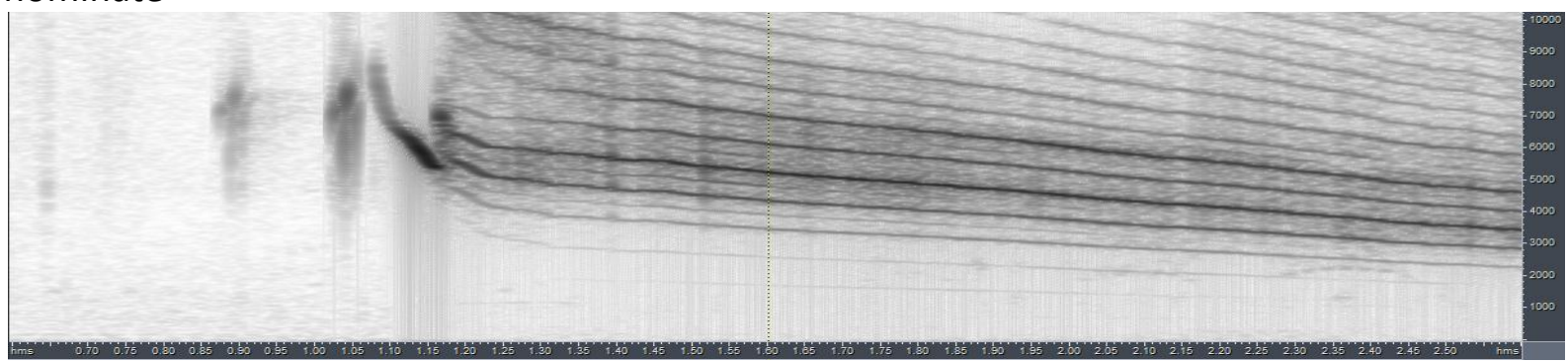

Difference in call notes has also been described (Schulenberg et al. 2007), although available recordings are scarce and indicate existence of several call types. More recordings are needed to get a better understanding of racial differences.

In summary, vocal difference could thus be scored based on song of peruvianus having a higher number of initial notes (score 3), a longer sizzling note (score 2) lacking any frequency drop (score 3 ) consisting of a very fast series of separate notes rather than a continuous nasal note (note 3 ), and often ending with a short high-pitched note (1).

When applying Tobias criteria, this would lead to a total vocal score of about 6.

We have no voice information about birds from Panama (parvus).

This note was finalized on 3rd May 2016, using sound recordings available on-line at that moment. We would like to thank in particular the many sound recordists who placed their recordings for this species on XC. 


\section{References}

Schulenberg, T.S., Stotz, D.F., Lane, D.F., O’Neill, J.P. \& Parker, T.A. (2007). Birds of Peru. Princeton University Press, Princeton, New Jersey.

Tobias, J.A., Seddon, N., Spottiswoode, C.N., Pilgrim, J.D., Fishpool, L.D.C. \& Collar, N.J. (2010). Quantitative criteria for species delimitation. Ibis 152(4): 724-746.

\section{Recommended citation}

Boesman, P. (2016). Notes on the vocalizations of Yellowish Pipit (Anthus lutescens). HBW Alive Ornithological Note 349. In: Handbook of the Birds of the World Alive. Lynx Edicions, Barcelona. (retrieved from http://www.hbw.com/node/1252880 on 27 October 2016). 